\title{
Multi-Objective Low-Carbon Economic Dispatch Considering Demand Response with Wind Power Integrated Systems
}

\author{
Liu Wenjuan ${ }^{1}$, Song Yundong ${ }^{2}$, Zhang Junru², Liu Yang ${ }^{2}$ and Meng Tao ${ }^{3}$ \\ ${ }^{1}$ Provincial Electric Power Co. Ltd, Shenyang 110006, China \\ ${ }^{2}$ Electric Power Research institute Liaoning Electric Power Company Limited, Shenyang 110006, China \\ ${ }^{3}$ Electric Power Research institute of Jilin Electric Power Co. of State Grid, Changchun 130021, China
}

\begin{abstract}
The generation cost, carbon emissions and customers' satisfaction are considered in this paper. On the basis of this, the multi-objective and low-carbon economic dispatch model with wind farm, this considers demand response, is established. The model user stochastic programming theory to describe the uncertainty of the wind power and converts it into an equivalent deterministic model by using distribution function of wind power output, optimizes demand side resources to adjust the next day load curve and to improve load rate and absorptive capacity of wind power, introduce customers' satisfaction to ensure that the scheduling scheme satisfies customer and integrate the resources of source and load to unify coordination wind farm access to network and to meet the requirements of energy saving and emission reduction. The search process of artificial fish school algorithm introducing Tabu search and more targeted search mechanism, an multi-objective improved artificial fish school algorithm is proposed to solve this model. Using the technique for order preference by similarity to ideal solution (TOPSIS) to sort the Pareto frontier, the optimal scheduling scheme is determined. Simulation results verify the rationality and validity of the proposed model and algorithm.
\end{abstract}

\section{Introduction}

As the greenhouse effect intensifying and fossil energy depletion, energy conservation and emissions reduction as the main target for the development of electric power enterprises. The carbon emissions of electric power enterprises mainly come from the large thermal power plants, thus we should change the traditional dispatching model to insure the economy and low carbon development of power system [1]. Compare with other new energy power generation, the wind power have lots of advantages: technology mature, low cost, clean and efficient. But large-scale wind power access to the power system will increase the difficulty of dispatching for the random output characteristics of wind power [2].

This problem is studied by related scholars. Literature [3] consider the randomness of wind power, and the dynamic scheduling model is established based on the stochastic programming theory. In literature [4], the dispatching question with wind power under extreme cases is change into a two-person zero-sum game between nature and decision-makes, and the robust optimization theory is used to describe the uncertainty output of wind power. On the other hand, considering the influence of the demand side resources in the process of dispatching, and unifying the resources between sources and loads to coordinate with wind power. In literature [5], the demand response resources is used as an virtual power generation to participate dispatching, and a low carbon dispatching model is established to improve the given capacity of wind power. In literature [6], the charge cars is introduced to coordination optimization dispatching, and by adjusting the weights of the indexes to implements the effective compromise between economy and carbon emissions.

In this paper, the strategy of demand response is introduced into low carbon and economic dispatching. In order to improve the given capacity of wind power, three power resources (wind power, thermal power, demand response) is considered in this paper. Firstly, application of wind power output distribution function, the multiobjective chance-constrained programming model is transformed into a deterministic model. Then, a multiobjective fish algorithm and the close to ideal solution sorting method are used to determine the optimal dispatching scheme. Lastly, by testing improved 10 machine system to verify the rationality and validity of proposed model and algorithm.

\section{Stochastic model of wind power}

A large amount of wind speed data analysis results show that the double parameter Weibull distribution can accurately describe the actual wind speed, and the distribution function is:

$$
F(v)=1-\exp \left(-(v / c)^{k}\right)
$$


where $k, c$ respectively show the distribution and scale parameters; $v$ is the wind speed.

The corresponding probability density function is:

$$
f(v)=(k / c)(v / c)^{k-1} \exp \left[-(v / c)^{k}\right]
$$

When know the wind speed distribution of the specific, through the analysis of the data of active output wind turbines and wind speed, the approximate function relation can be obtained, which can acquire from Fig. 1.

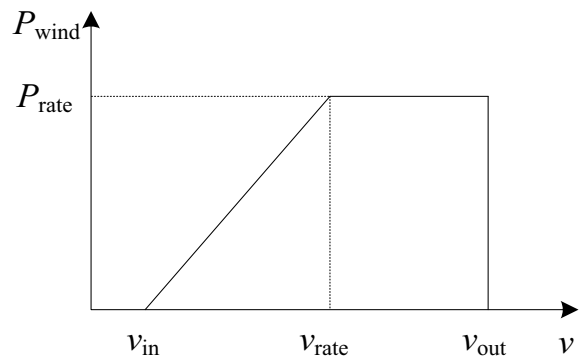

Figure 1. The active power output of wind power

From Fig. 1 we can see that the relationship of active power output of wind power $\left(P_{\text {wind }}\right)$ and wind speed can be acquire:

$$
P_{\text {wind }}=\left\{\begin{array}{l}
0, \quad v \leq v_{\text {in }} \text { or } v \geq v_{\text {out }} \\
P_{\text {rate }} \frac{v-v_{\text {in }}}{v_{\text {rate }}-v_{\text {in }}} \quad v_{\text {in }} \leq v \leq v_{\text {rate }} \\
P_{\text {rate }} \quad v_{\text {rate }} \leq v \leq v_{\text {out }}
\end{array}\right.
$$

where $v_{\text {in }}, v_{\text {out }}, v_{\text {rate }}$ respectively cut in, cut out and rated wind speed; Prate is rated active power of wind power.

According to type (3) we can acquire the distribution function of $P_{\text {wind }}$ :

$$
F\left(P_{\text {wind }}\right)=\left\{\begin{array}{l}
0, \quad P_{\text {wind }}<0 \\
1-\exp \left\{-\left[\left(1+\frac{v_{\text {rate }}-v_{\text {in }}}{v_{\text {in }} P_{\text {rate }}} P_{\text {wind }}\right) \frac{v_{\text {in }}}{c}\right]^{k}\right\} \\
+\exp \left[-\left(\frac{v_{\text {out }}}{c}\right)^{k}\right], \quad 0 \leq P_{\text {wind }} \leq P_{\text {rate }} \\
1 \\
P_{\text {wind }} \geq P_{\text {rate }}
\end{array}\right.
$$

\section{User satisfaction index}

User satisfaction is measured by the experience of power user after the implementation of time-of-use price (TOU), which mainly include user electricity expenses satisfaction and electricity ways satisfaction index. User electricity expenses satisfaction index can be described as follow:

$$
\theta=1-\frac{\sum_{t=1}^{T}\left(L_{j}^{t} p_{t}-L_{j 0}^{t} p_{0}\right)}{\sum_{t=1}^{T} L_{j 0}^{t} p_{0}}
$$

where $\theta$ is the electricity expenses satisfaction; $P_{t}, L_{j}^{t}$ respectively electricity price and load on $t$ section after the implementation of TOU; $T$ is the dispatching cycle; $p_{0}$,
$L_{j 0}^{t}$ respectively electricity price and load before the implementation of TOU.

User electricity expenses satisfaction index $\theta$ is higher, which shows that the electricity expenses satisfaction is greater. When $\theta>1$, which illustrate that the electricity expenses of user is decreased.

Electricity way satisfaction index $\lambda$ is described the implementation of TOU user power consumption before and after the change of time, which can be acquired as follow:

$$
\lambda=1-\frac{\sum_{t=1}^{T}\left|\left(L_{j}^{t}-L_{j 0}^{t}\right)\right|}{\sum_{t=1}^{T} L_{j 0}^{t}}
$$

\section{Multi-objective optimization model}

\subsection{Multi-objective function}

(1) Minimize the conventional generating units of the total cost of objective function is:

$$
\min F_{1}=\sum_{t=1}^{T} \sum_{i=1}^{N}\left[I_{i, t} f_{i, t}\left(P_{i, t}\right)+I_{i, t}\left(1-I_{i, t-1}\right) S_{i, t}\right]
$$

where $F_{1}$ is the total cost of the conventional power generation unit; $T$ is the scheduling cycle; $N$ is the number of conventional unit; $I_{i, \mathrm{t}}=0$ and $I_{i, t}=1$ respectively the operation and stop station of the $i$ th conventional unit under $t$ time; $P_{i, t}$ is the output power of $i$ th conventional unit; $S_{i, t}$ is the control cost of $i$ th conventional unit.

The fuel costs of conventional units is:

$$
f_{i, t}\left(P_{i, t}\right)=a_{i} P_{i, t}^{2}+b_{i} P_{i, t}+c_{i}
$$

where $a_{i}, b_{i}, c_{i}$ are the energy consumption parameters of the units.

The start-stop costs of conventional units is:

$$
S_{i, t}= \begin{cases}h_{\mathrm{s} i} & M_{\mathrm{D} i} \leq X_{i, t}^{\mathrm{off}} \leq M_{\mathrm{D} i}+T_{i} \\ c_{\mathrm{s} i} & X_{i, t}^{\mathrm{off}} \geq M_{\mathrm{D} i}+T_{i}\end{cases}
$$

where $h_{s i}$ and $c_{s i}$ respectively for the hot-start and coldstart costs of the ith convention units; $M_{D i}$ is the minimum outage time of the ith convention units; $X_{i, t}^{\text {off }}$ is the continuous stoppage time of the ith convention units.

(2) Minimize the conventional generating units of the total carbon emissions of objective function is:

$$
\min F_{2}=\sum_{t=1}^{T} \sum_{i=1}^{N}\left[C\left(P_{i, t}\right) I_{i, t}\right]
$$

where $F_{2}$ is the carbon emissions of conventional units under total scheduling cycle; $C\left(P_{i, t}\right)$ is the carbon emissions, and the characteristic equation can be represented as:

$$
C\left(P_{i, t}\right)=\alpha_{i}+\beta_{i} P_{i, t}+\gamma_{i} P_{i, t}
$$

where $\alpha_{i}, \beta_{i}, \gamma_{i}$ are the carbon emission coefficient. 


\subsection{Constraints}

(1) Power balance constraint:

$$
\sum_{i=1}^{N} P_{i, t}+P_{\mathrm{w}, \mathrm{t}}-P_{\mathrm{D}, t}-P_{\text {loss }, t}=0
$$

where $\mathrm{Pw}, \mathrm{t}$ is power output of wind farm under $\mathrm{t}$ station; $\mathrm{PD}, \mathrm{t}$ is the system load after TOU under t station; Ploss, $\mathrm{t}$ is network loss under $t$ station.

(2) Wind power penetration limit constraint:

$$
P_{\mathrm{w}, t} \leq \delta P_{\mathrm{D}, t}
$$

where $\delta$ is penetration limit coefficient, by the method of chance constrain which can be expressed as:

$$
P\left\{\delta P_{\mathrm{D}, t} \geq P_{\mathrm{w}, t}\right\} \geq \varphi
$$

where $\varphi$ is limit constraints to satisfy the confidence level of wind farm.

(3) Output power constraint of conventional unit:

$$
P_{i, \min } \leq P_{i, t} \leq P_{i, \max }
$$

(4) Minimum open-stop time constraint of conventional unit:

$$
\begin{cases}\left(1-I_{i, t+1}\right) M_{\mathrm{U} i} \leq X_{i, t}^{\mathrm{on}} & I_{i, t}=1 \\ I_{i, t+1} M_{\mathrm{D} i} \leq X_{i, t}^{\mathrm{off}} & I_{i, t}=0\end{cases}
$$

(5) Positive and negative reserve capacity constraint of conventional unit:

$$
\begin{aligned}
& \sum_{i=1}^{N}\left(P_{i, \max }-P_{i, t}\right) \geq P_{\mathrm{D}, t}^{\mathrm{up}} \\
& \sum_{i=1}^{N}\left(P_{i, t}-P_{i, \text { min }}\right) \geq P_{\mathrm{D}, t}^{\mathrm{down}}
\end{aligned}
$$

(6) In order to guarantee the electricty ways of user does not significantly change, and the electricity way satisfaction index should be satisfied as:

$$
\lambda \geq \lambda_{\text {min }}
$$

(7) In order to guarantee the interests of user don't damage after TOU, and the electricity expenses satisfaction index should to meet:

$$
\theta \geq \theta_{\min }
$$

(8) Open ratio should to meet:

$$
Q_{p} / Q_{v} \leq \omega \leq 1
$$

\section{Multi-objective optimization algorithm}

\subsection{Improved multi-objective artificial fish school algorithm}

Artificial fish school algorithm (AFSA) and Tabu search algorithm (TS) is combined in this paper, and an improved artificial fish school algorithm (IAFSA) is proposed to improve the ability of global optimal converge. The strategies of crowding distance calculation, accumulated sort and elite reserve are introduced to make IAFSA is suitable to solve multi-objective optimization scheduling problem. Thus, the multi-objective improved artificial fish school algorithm (MIAFSA) is proposed to deal with this model, and its process can be shown in Fig. 2 .

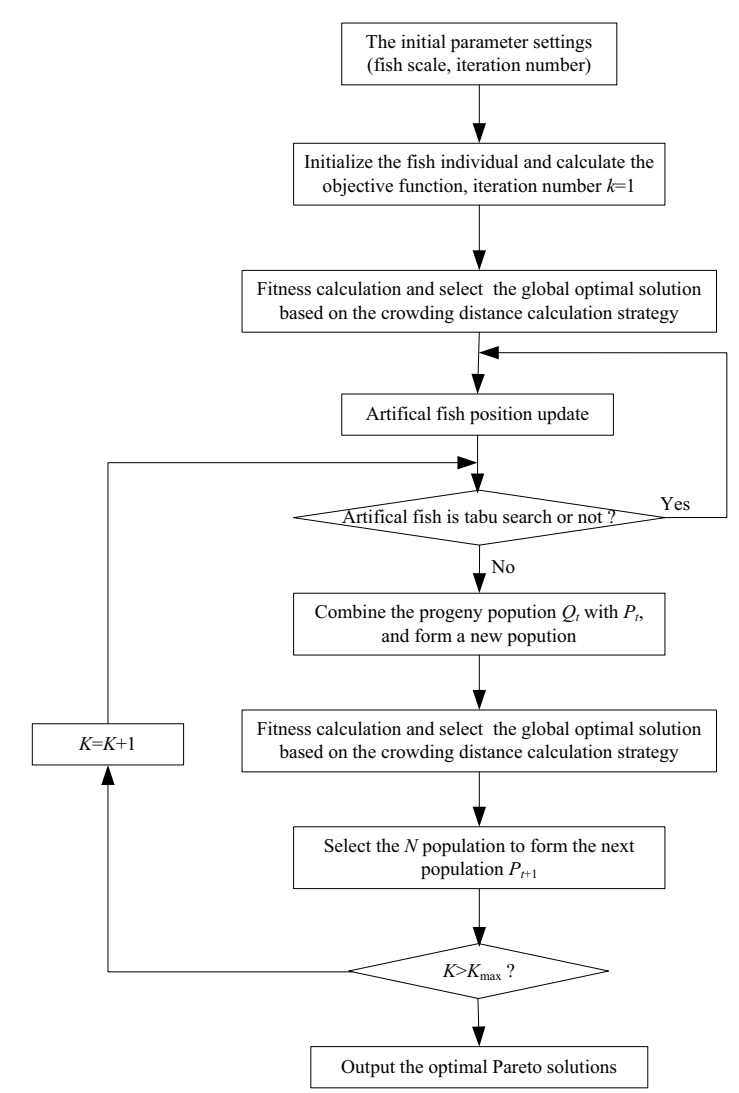

Figure 2. Ther process of MIAFSA

\subsection{Multi-objective dispatching steps}

(1) Input unit parameters, user response parameters, wind power prediction parameters, original electricity price and load parameters.

(2) Determine the period of electricity price, and calculate the electricity price of peak and low times.

(3) According to the principle of consumer psychology calculated system load, user electricity expenses satisfaction index and electricity way satisfaction index after TOU.

(4) Judge the related index whether meet the constraints or not, if meet in step (5), or else, turn into step (2).

(5) According to step (3) calculate the system load, and arrange the unit combination and output, and calculate the total cost and carbon emissions.

(6) Use the MIAFSA algorithm calculate the optimal Pareto solutions.

(7) Judge whether meet the maximum number of iterations or not, if meet, output the optimal Pareto solution set, or turn into step (2).

\section{Example analisis}

Typical 10 machibe systems with wind farms is tested in this paper. The scheduling cycle is one day, and it can be divided into 24 periods. The confidence level $\mu$ and $\varphi$ 
respectively 0.95 and 0.85 . Ordinary electricity price is $0.8 \mathrm{RMB} / \mathrm{kW} . \mathrm{h}$, and peak-ping-gu time period can be divided into: 9:00-15:00 and 20:00-22:00 are peak period; 6:00-9:00, 15:00-17:00, 18:00-20:00 and 22:00-23:00 are ping period; 23:00-6:00 and 17:00-18:00 are gu period. Wind farms contain 60 fan, and the related power is 2 $\mathrm{MW}$, and the forecast output power in 24 hour can be shown in Fig. 3. Positive and negative rotation of spare capacity in each period are $5 \%$ of the system load, wind power penetration limit coefficient is 0.09 . MIAFSA parameters setting: artificial scale is 80 ; iteration number is 100 ; crowd coefficient is 0.3 ; biggest foraging number is 10; the length of the Tabu table is 10. The Pareto front acquired based on MIAFSA can be shown in Fig. 4, and the diversity solutions can be shown in Table 1 .

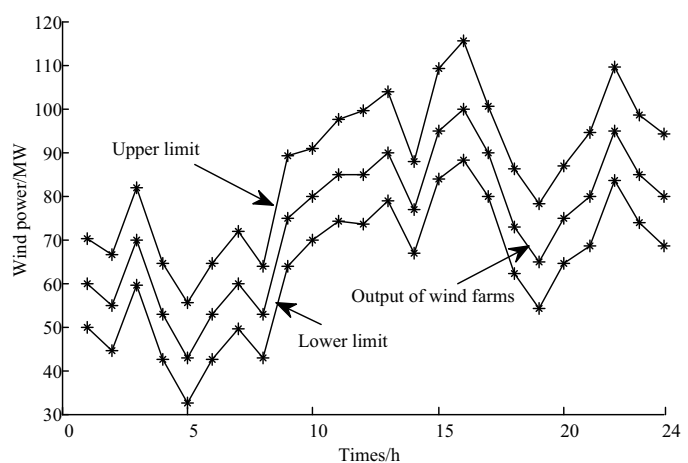

Figure 3. Ther output of wind farms and fluctuation range

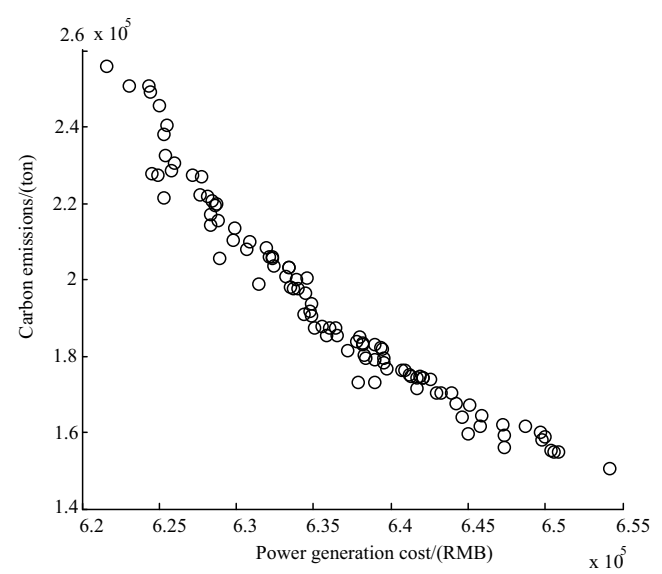

Figure 4. Ther Pareto front based on MIAFSA

From Fig. 4 we can see that the Pareto front integrity is better, and the distribution range of carbon emission is better than the power generation cost, which is mainly due to the conventional units difference is larger.

According to the data of Table 1, compared with the PSO algorithm, the power generation cost and carbon emissions of optimal solution respectively decrease 7630 RMB and 17360 ton; the electricity expense satisfaction index is approaching to 1 , which indicate that the user electricity expense has decreased after TOU, but no serious damage to the power gird company's benefits. Electricity way satisfaction index is higher, which see that the daily electricity use way of user didn't upset after TOU. Opening ratio as an important index of electricity price, which directly decides the peak-valley price. The greater of the index show that the user response more fully with TOU, and peak sharpening effect is more obvious, which accord with the consumer psychology of user. The start-stop cost of units and power generation cost has no obvious relationship, but there are positively correlated with carbon emissions, which show that the frequent start-stop of units is help reduce the carbon emissions of system because of the carbon emission characteristics of small capacity unit is less. The accept ability of wind power under traditional method is $1762 \mathrm{MW}$, in this paper, the accept ability is improve $7 \mathrm{MW}, 19 \mathrm{MW}, 15 \mathrm{MW}$ respectively under economic optimal, environment optimal and optimal solution station. Thus, compared with the traditional method, the accept ability of wind power of system is improved with demand response considered. From another hand, the peak-valley of load is decreased $334 \mathrm{MW}$, which see that the load rate of system is improved with demand response considered.

The load curve with demand response considered before and after can be shown in Fig. 5. To test the authenticity of the dispatching results, the optimal solution is given in Table 2 .

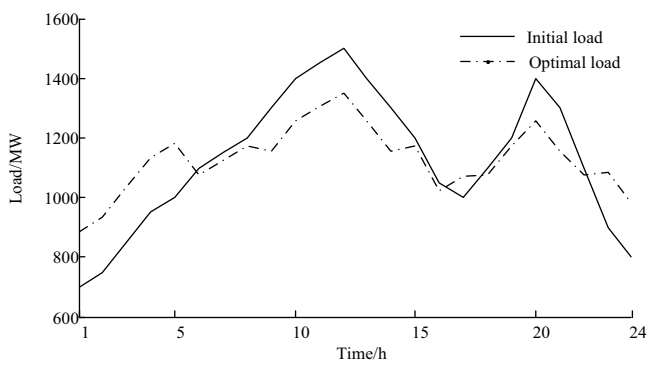

Figure 5. The load curve with demand response considered

Table 1. The diversity solutions under low carbon economic dispatching.

\begin{tabular}{ccccccccc}
\hline objects & $\begin{array}{c}\text { Generation } \\
\text { cost } \\
/\left(10^{5} \mathrm{RMB}\right)\end{array}$ & $\begin{array}{c}\text { Carbon } \\
\text { emission/(10 }\end{array}$ & $\begin{array}{c}\text { electricity } \\
\text { expenses } \\
\text { satisfaction }\end{array}$ & $\begin{array}{c}\text { Electricity } \\
\text { way } \\
\text { satisfaction }\end{array}$ & $\begin{array}{c}\text { Control } \\
\text { cost } \\
/(\mathrm{RMB})\end{array}$ & $\begin{array}{c}\text { Opening } \\
\text { ratio }\end{array}$ & $\begin{array}{c}\text { Peak valley } \\
\text { difference } \\
/(\mathrm{MW})\end{array}$ & $\begin{array}{c}\text { Wind } \\
\text { power } \\
/(\mathrm{MW})\end{array}$ \\
\hline $\begin{array}{c}\text { Economic } \\
\text { optimal }\end{array}$ & 6.2161 & 2.5578 & 1.0102 & 0.8700 & 4200 & 0.8120 & 472 & 1769 \\
$\begin{array}{c}\text { Environment } \\
\text { optimal }\end{array}$ & 6.5418 & 1.5067 & 1.1424 & 0.9105 & 3970 & 0.6536 & 425 & 1781 \\
$\begin{array}{c}\text { Optimal } \\
\text { solution } \\
\text { PSO }\end{array}$ & 6.3491 & 1.9045 & 1.0841 & 0.8996 & 4190 & 0.7011 & 466 & 1777 \\
algorithm & 6.4254 & 2.0781 & 1.0721 & 0.9007 & 4260 & 0.6914 & 455 & 1775 \\
\hline
\end{tabular}


Table 2. Pareto solution of MIAFSA.

\begin{tabular}{|c|c|c|c|c|c|c|c|c|c|c|c|c|c|}
\hline \multirow{2}{*}{ period } & \multicolumn{10}{|c|}{ The output of units under different period /MW } & \multirow{2}{*}{$\begin{array}{c}\text { Access } \\
\text { ability } \\
\text { /MW }\end{array}$} & \multirow{2}{*}{$\begin{array}{l}\text { Network } \\
\text { loss /MW }\end{array}$} & \multirow{2}{*}{$\begin{array}{l}\text { Load } \\
\text { /MW }\end{array}$} \\
\hline & unit1 & unit2 & unit3 & unit4 & unit5 & unit6 & unit7 & unit8 & unit9 & Unit10 & & & \\
\hline 1 & 356.21 & 174.93 & 44.93 & 44.93 & 49.93 & 80 & 0 & 34.9 & 55 & 0 & 62 & 16.61 & 886.24 \\
\hline 2 & 218.08 & 218.08 & 88.08 & 88.08 & 93.08 & 80 & 0 & 55 & 0 & 55 & 55 & 16.18 & 934.24 \\
\hline 3 & 257.30 & 257.30 & 127.3 & 130 & 132.3 & 80 & 0 & 0 & 0 & 0 & 70 & 19.97 & 1034.2 \\
\hline 4 & 319.6 & 257.4 & 130 & 127.4 & 132.4 & 0 & 85 & 0 & 55 & 0 & 53 & 25.52 & 1134.2 \\
\hline 5 & 331.51 & 331.51 & 130 & 130 & 162 & 0 & 85 & 0 & 0 & 0 & 43 & 29.18 & 1183.8 \\
\hline 6 & 306.73 & 306.73 & 130 & 0 & 162 & 0 & 85 & 0 & 55 & 0 & 53 & 24.14 & 1074.4 \\
\hline 7 & 357.36 & 357.36 & 130 & 0 & 162 & 0 & 85 & 0 & 0 & 0 & 60 & 27.45 & 1124.2 \\
\hline 8 & 414.88 & 403.38 & 71.79 & 0 & 76.79 & 0 & 76.8 & 55 & 55 & 0 & 53 & 31.92 & 1174.7 \\
\hline 9 & 309.76 & 309.76 & 130 & 0 & 162 & 0 & 85 & 0 & 55 & 55 & 75 & 26.70 & 1154.8 \\
\hline 10 & 359.89 & 359.89 & 130 & 0 & 162 & 0 & 85 & 55 & 55 & 0 & 80 & 32.13 & 1254.9 \\
\hline 11 & 345.56 & 345.56 & 130 & 130 & 162 & 0 & 85 & 0 & 0 & 55 & 85 & 33.30 & 1304.8 \\
\hline 12 & 340.63 & 455 & 130 & 130 & 162 & 0 & 85 & 0 & 0 & 0 & 85 & 37.31 & 1350.3 \\
\hline 13 & 375.16 & 288.78 & 130 & 130 & 162 & 0 & 0 & 55 & 0 & 55 & 90 & 30.80 & 1255.1 \\
\hline 14 & 329.67 & 353.50 & 130 & 130 & 162 & 0 & 0 & 0 & 0 & 0 & 77 & 27.27 & 1154.9 \\
\hline 15 & 286.83 & 286.83 & 130 & 130 & 161.8 & 0 & 0 & 0 & 55 & 55 & 95 & 25.79 & 1174.7 \\
\hline 16 & 253.41 & 253.41 & 123.4 & 130 & 128.4 & 0 & 0 & 0 & 55 & 0 & 92 & 18.94 & 1022.8 \\
\hline 17 & 270.56 & 270.56 & 130 & 130 & 145.6 & 0 & 0 & 55 & 0 & 0 & 90 & 21.18 & 1070.4 \\
\hline 18 & 301.28 & 301.28 & 130 & 130 & 162 & 0 & 0 & 0 & 0 & 0 & 73 & 23.02 & 1074.7 \\
\hline 19 & 330.22 & 330.22 & 130 & 130 & 162 & 0 & 0 & 0 & 55 & 0 & 65 & 28.22 & 1174.2 \\
\hline 20 & 339.78 & 339.78 & 130 & 130 & 162 & 0 & 0 & 0 & 55 & 55 & 75 & 31.72 & 1254.9 \\
\hline 21 & 284.17 & 284.17 & 130 & 130 & 162 & 0 & 0 & 55 & 0 & 55 & 80 & 25.30 & 1155.5 \\
\hline 22 & 270.38 & 270.38 & 130 & 130 & 145.3 & 0 & 0 & 0 & 0 & 55 & 95 & 21.42 & 1074.8 \\
\hline 23 & 243.19 & 243.19 & 130 & 113.1 & 125.9 & 0 & 0 & 55 & 55 & 55 & 85 & 21.29 & 1084.2 \\
\hline 24 & 235.06 & 235.06 & 130 & 105.0 & 162 & 0 & 0 & 0 & 0 & 55 & 80 & 17.94 & 984.55 \\
\hline
\end{tabular}

\section{Conclusion}

(1) A multi-objective chance constrained program model of environment, economy and user satisfaction is established in this paper, which change the traditional economic dispatching pattern to provide a more comprehensive reference solution to decision makes.

(2) Demand response is introduced into low carbon economic dispatching can effectively cut peak-valley load difference, increase the load ability of system and the access ability of wind power.

\section{References}

1. S. Roy, Inclusion of short duration wind variations in economic load dispatch. IEEE Transactions on Sustainable Energy, 3(2): 265-273 (2012)
2. S.W. Mei, W.T. Guo, Y.Y. Wang, et al. A game model for robust optimization of power systems and its application. Proceeding of the CSEE, 33(19): 4756 (2013)

3. R. Billinon, G. Baig. Generating capacity adequacy associat- ed with wind energy. IEEE Transactions on Energy Systems, 19(3): 641-646 (2004)

4. W. Zhou, Y. Peng, H. Sun, et al. Dynamic economic dispatch in wind power integrated system. Proceeding of the CSEE, 29(25): 13-18 (2009).

5. X. Liu, X. Ai, Q. Peng. Optimal dispatch coordinating power generation with carbon emission permit for wind farms integrated power grid considering demand response. Power System Technology, 36(1): 213-218 (2012)

6. X. Liu, W. Xu, Economic load dispatch constrained by wind power availability: a here-and-now approach. IEEE Transactions on Sustainable Energy, 1(1): 2-9 (2010) 